\title{
Acquisition of PrtS in Streptococcus thermophilus is not enough in certain strains to achieve rapid milk acidification
}

\author{
Wessam Galia ${ }^{1,2,3}$ - Nawara Jameh ${ }^{1,2}$. \\ Clarisse Perrin $^{1,2} \cdot$ Magali Genay ${ }^{1,2}$. \\ Annie Dary-Mourot ${ }^{1,2}$
}

Received: 23 March 2016 /Revised: 19 May 2016/Accepted: 19 May 2016/

Published online: 7 June 2016

(C) INRA and Springer-Verlag France 2016

\begin{abstract}
The acquisition of prtS by Streptococcus thermophilus strains allowed hydrolysis of caseins into peptides and then to increase their growth in milk. This leads to faster milk acidification, which is important in dairy industry. However, some strains harboring the same allele of $p r t S$ present different acidification rates, which could be explained by a difference in the regulation of $p r t S$ expression. We chose two strains with the same allele of prtS (including the same promoter region): one, $\mathrm{PB} 302$, is with high acidification rate while the other, PB180, is without. They exhibited similar growth in M17, but not in milk, where PB302 showed better growth. The expression of $p r t S$ and activity of PrtS were lower in PB18O, in the two media tested. We demonstrated that other genes known to be involved in carbon and nitrogen metabolism were overexpressed in PB302. Interestingly, these genes were overexpressed in milk compared to M17. Nearly all these genes possessed a putative CodY-box in their promoter region. Taken together, difference of gene expression detected in PB302 between milk (low-peptide medium) and M17 (rich-peptide medium) and presence of a putative CodY-box is a feature of the transcriptional pattern of CodY-regulated genes. Altogether, our results propose that acquisition of $p r t S$ is not enough in certain strains to achieve rapid milk acidification. High transcriptional level of $d t p T, a m i F, i l v C, i l v B, b c a T, \operatorname{liv} J$, ackA, codY, and $p r t S$ in fast acidifying strain suggests that this transcriptional pattern could be required for fast milk acidification in Streptococcus thermophilus.
\end{abstract}

Magali Genay

magali.genay@univ-lorraine.fr

1 Unité de Recherche Animal et Fonctionnalités des Produits Animaux, Equipe Protéolyse et Biofonctionnalité des Protéines et des Peptides, Université de Lorraine,

Vandœuvre-lès-Nancy 54506, France

2 UR AFPA Unité Sous Contrat 340, INRA, Vandœuvre-lès-Nancy 54506, France

3 Present address: Research Group on Bacterial Opportunistic Pathogens and Environment, UMR 5557 Ecologie Microbienne, CNRS, VetAgro Sup, and Université Lyon 1, Université de Lyon, Lyon, France 
Keywords Proteolytic system $\cdot$ Transcriptional regulation $\cdot \operatorname{PrtS} \cdot \mathrm{CodY} \cdot$ Streptococcus thermophilus

\section{Introduction}

Milk acidification rate, which is of major technological importance in dairy industry, is dependent on the growth rate of lactic acid bacteria (LAB). Among them, Streptococcus thermophilus is widely used for its ability to acidify the milk and to produce aromatic compounds. Several studies have demonstrated the existence of a link between rapid growth of Streptococcus thermophilus in milk, high acidifying capacity, and presence of an efficient proteolytic system (Courtin et al. 2002; Dandoy et al. 2011; Galia et al. 2009). Indeed, the concentration in small peptides and free amino acids in milk is low. To grow at a high cellular density, LAB need to overcome their auxotrophy for certain amino acids by hydrolyzing milk caseins to benefit from an amino acid source. For this, LAB possess a proteolytic system which is generally composed of a cell-envelope proteinase (CEP) that initiates the casein breakdown, transport systems which internalize resulting oligopeptides through the membrane and various intracellular peptidases which hydrolyze them to free amino acids (Savijoki et al. 2006). Most of LAB possess only one CEP but some lactobacilli strains harbor two or more CEPs (Genay et al. 2009; Broadbent et al. 2011). In Streptococcus thermophilus, prtS belongs to a genomic island probably acquired by horizontal transfer from a commensal and/or pathogenic species close to Streptococcus suis (Delorme et al. 2010). It has been shown in Streptococcus thermophilus that the presence of the cell-envelope proteinase PrtS was a prerequisite for a high acidification rate of milk (Galia et al. 2009; Dandoy et al. 2011; Urshev et al. 2014), but some strains possessing the prtS gene exhibited nevertheless a low acidification rate (Galia et al. 2009). This difference in acidifying rate did not result from a mutation in the prtS gene, as fast acidifying and lower acidifying strains harbored a $100 \%$ identical allele including the promoter region (Galia et al. 2009). These results suggest that the expression of prtS may be regulated differently in the different strains. Analysis of the upstream region of prtS revealed the presence of a binding motif recognized by the protein CodY (Galia et al. 2009), and gel shift experiments have confirmed that the CodY protein of Streptococcus thermophilus was able to bind to the promoters of 14 genes belonging to proteolytic system including prtS (Liu et al. 2009). This suggests that the variation of the acidifying capacity observed between the different strains of Streptococcus thermophilus could be due to a different regulation of the expression of $p r t S$ and may be through CodY.

CodY is a pleiotropic transcriptional regulator found in Gram-positive bacteria with low-GC percent, which represses the expression of over 100 to 200 genes involved in various metabolic pathways and functions (Guédon et al. 2005; den Hengst et al. 2005; Lu et al. 2015). In pathogenic streptococci, CodY is also a key regulator and controls several factors of virulence such as the adhesion of Streptococcus pyogenes (Hendriksen et al. 2008). A consensus DNA binding sequence of CodY (AATTTTCWGAAAATT) has been established in Lactococcus lactis, Bacillus subtilis, Streptococcus pneumoniae, Listeria monocytogenes, and Streptococcus thermophilus (Belintsky and Sonenshein 2008; Guédon et al. 2005; den Hengst et al. 2005; Lu et al. 2015). CodY is mostly known to be a repressor although it can sometimes function as 
an activator, as it is the case for the $b s r F$ and the ackA (acetate kinase) genes in Bacillus subtilis (Preis et al. 2009; Shivers et al. 2006). In Streptococcus thermophilus, CodY repressed the conversion of carbon source into amino acids and improved lactose utilization, allowing the bacterium to adapt to the milk environment ( $\mathrm{Lu}$ et al. 2015).

The objective of this work was to investigate why some strains of Streptococcus thermophilus having the same allele of prtS may exhibit significantly different proteolytic activity at the cell surface. For this, we focused on two strains phylogenetically close (Junjua et al. 2016): the PB302 strain presents a high acidification rate and a significant proteolytic activity, whereas PB18O, which carries the same allele of prtS as PB302, seems to be slightly proteolytic, with a much slower milk acidification rate (Galia et al. 2009). We particularly studied in these two strains the expression of prtS and other genes involved in carbon and nitrogen metabolism, in order to identify the transcriptional pattern that could be correlated with the fast acidifying phenotype of Streptococcus thermophilus in milk.

\section{Materials and methods}

\subsection{Bacterial strains and growth conditions}

The strains used in this work, PB302, isolated from yoghurt, and PB18O, isolated from cheese, were stored at $-80{ }^{\circ} \mathrm{C}$ in reconstituted skim milk $(10 \% w / v)$. Cultures were incubated overnight at $42{ }^{\circ} \mathrm{C}$ in reconstituted skim milk before each experiment. Precultures were inoculated to $1 \%$ in milk or M17 (Terzaghi and Sandine 1975), and cultures were incubated at $42{ }^{\circ} \mathrm{C}$ without shaking until the required growth stage was reached. Bacterial growth was monitored by measuring optical density (OD) at $650 \mathrm{~nm}$ for M17 or at $480 \mathrm{~nm}$ after clarification of the milk by a 10 -fold dilution in 2 g.L $\mathrm{L}^{-1}$ EDTA pH 12 (Thomas and Turner 1977).

\subsection{Detection of proteolytic activity}

The proteolytic activity present at the cell-surface of bacteria cultivated in milk or in M17 media was evaluated using the substrate Suc-Ala-Ala-Pro-Phe- $p$ NA. The synthetic substrate was prepared at $2 \mathrm{mmol.L} \mathrm{L}^{-1}$ in 1 volume of N,N-dimethylformamide and 9 volumes of Tris- $\mathrm{HCl}$ buffer 50 mmol.L ${ }^{-1}(\mathrm{pH} 7.5)+5 \mathrm{mmol} \cdot \mathrm{L}^{-1} \mathrm{CaCl}_{2}$. Another chromogenic substrate, Lys- $p$ NA, prepared as for Suc-Ala-Ala-Pro-Phe- $p$ NA, was used to check the absence of peptidase activity in the culture supernatant.

When strains were grown in M17 cultures, cells were recovered from 10-mL growth medium by centrifugation for $15 \mathrm{~min}$ at $3900 \mathrm{~g}$ and $4{ }^{\circ} \mathrm{C}$ and pellets were washed and resuspended in Tris- $\mathrm{HCl}$ buffer $100 \mathrm{mmol} . \mathrm{L}^{-1} \mathrm{pH} 7.0$ to obtain a cell concentration of $5.10^{8} \mathrm{CFU} \mathrm{mL}{ }^{-1}\left(\mathrm{OD}_{650 \mathrm{~nm}}=1\right)$. When strains were grown in milk, caseins were first eliminated by adding to 40 volumes of fermented milk, 5.3 volumes of saline solution $(\mathrm{NaCl} 0.85 \%$; sodium glycerophosphate $0.5 \%$; Tween $800.1 \%$; $\mathrm{pH} 7$ ), and 1.3 volume of trisodium citrate 1 mol. $\mathrm{L}^{-1}$ (Chopard et al. 2001). Pellets were recovered by centrifugation for $15 \mathrm{~min}$ at $3900 \mathrm{~g}$ and $4{ }^{\circ} \mathrm{C}$, washed and resuspended in Tris- $\mathrm{HCl}$ buffer 100 mmol.L $\mathrm{L}^{-1} \mathrm{pH} 7.0$ to obtain a cell concentration of $5.10^{8} \mathrm{CFU} \mathrm{mL}^{-1}$. One hundred microliters of bacterial suspensions were incubated with $1 \mathrm{~mL}$ of substrate 
during 1 h30 at $37{ }^{\circ} \mathrm{C}$. After incubation, cells were removed by centrifugation and absorbance of supernatants determined at $410 \mathrm{~nm}$ by spectrometry (Uvikon, Kontron, Switzerland). Assays were performed in triplicate on cells obtained from two independently grown cultures.

\subsection{Quantitative RT-PCR}

After growth in $45 \mathrm{~mL}$ of M17, bacterial cells were collected by centrifugation for $15 \mathrm{~min}$ at $3900 \mathrm{~g}$ and $4{ }^{\circ} \mathrm{C}$, frozen in liquid nitrogen and stored at $-80{ }^{\circ} \mathrm{C}$. After growth in $80 \mathrm{~mL}$ of milk, caseins have been removed as described above (Chopard et al. 2001) and bacterial pellets were resuspended in $46.6 \mathrm{~mL}$ of cold extraction buffer (sodium phosphate 5 mmol.L ${ }^{-1}$; EDTA 1 mmol.L ${ }^{-1} ; \beta$-mercaptoethanol 2 mmol.L ${ }^{-1}$; $\mathrm{pH}$ 7) (Derzelle et al. 2005; Guimont et al. 2002). After centrifugation for $15 \mathrm{~min}$ at $3900 \mathrm{~g}$ and $4{ }^{\circ} \mathrm{C}$, pellets were frozen in liquid nitrogen at $-80{ }^{\circ} \mathrm{C}$. Total RNAs were extracted according to Chomczynski using TRIzol reagent (Chomczynski 1993; Chomczynski and Sacchi 1987). DNA was removed by incubating for $30 \mathrm{~min}$ at $37{ }^{\circ} \mathrm{C}$ in the presence of $10 \mathrm{U}$ of DNAse I (Roche, Meylan, France) and $40 \mathrm{U}$ of RNase inhibitor (Rnase OUT, Invitrogen, Saint Aubin, France). RNA was purified by phenol-chloroform extraction (Green and Sambrook 2012) and then precipitated by adding a volume of cold isopropanol. The pellet was recovered by centrifugation for 20 min at 12,000 $\mathrm{g}$ and $4{ }^{\circ} \mathrm{C}$, washed with $70 \%$ ethanol and dissolved in MilliQ water. A second step of DNase was then performed using the TURBO DNA-free kit (Ambion, Courtaboeuf, France) for $90 \mathrm{~min}$ at $37^{\circ} \mathrm{C}$. Total RNA was quantified by measuring the absorbance at $260 \mathrm{~nm}$ using a spectrophotometer Nanodrop-1000 (Thermo Scientific, Illkirch, France). Complementary DNAs (cDNA) were synthesized from total RNA by using Moloney murine leukemia virus reverse transcriptase (Invitrogen, Saint Aubin, France) according to the manufacturer's instructions. Quantitative RT-PCR (qRT-PCR) reactions were performed on MJ Opticon Monitor (Biorad) using MESA GREEN SYBR Assay No ROX (Eurogentec, Seraing, Belgium) following the manufacturer's instructions. qPCR primers were designed with Primer3Plus software (Untergasser et al. 2007) to amplify approximately 130-bp fragments of tested genes (Table 1). Each reaction was carried out in triplicate and the overall experiment of qRT-PCR was done twice independently. Data were recorded as threshold cycles $(C T)$, expressed as means \pm SEM, and computed using the comparative critical threshold $\left(2^{-\Delta \Delta C T}\right)$ method (Livak and Schmittgen 2001). The results were normalized using the gene encoding the sigma factor $\sigma 70 / \sigma 32$ as reference gene, as it was expressed at a constant level under our conditions. An expression ratio higher than 2 or lesser than 0.5 observed in the two independent experiments was considered.

\section{Results}

\subsection{Growth of Streptococcus thermophilus PB18O and PB302 in milk and M17 media}

The strains PB302 and PB18O harbored the same allele of prtS (from 752 nt upstream of the start codon to $382 \mathrm{nt}$ downstream of the stop codon), but proteolytic and 
Table 1 Sequence and hybridization position of primers used in quantitative RT-PCR experiments

\begin{tabular}{|c|c|c|c|}
\hline Primers & Sequence & Gene (STER_\#) $)^{\mathrm{a}}$ & $\begin{array}{l}\text { Distance from } \\
\text { ATG }^{\text {b }}\end{array}$ \\
\hline amiFquantfor & CTTCCACGATTGTCCCCTTAT & $\operatorname{amiF}(1405)$ & +694 \\
\hline amiFquantrev & TTCGTGCCCAAGTTTTGAATTT & $\operatorname{amiF}(1405)$ & +553 \\
\hline AckAquantfor & CCCGCTGTAAAGACGATAGC & ackA (1834) & +992 \\
\hline AckAquantrev & TTGCTGGTAAAGAGGCTGGT & ackA (1834) & +862 \\
\hline lactquantfor & AACACGGCGACTCAGAGTTT & $l d h(1257)$ & +558 \\
\hline lactquantrev & TAAGCTGCATCACGAACACC & $l d h(1257)$ & +677 \\
\hline livJquantfor & TTGCGGCCTATGGTAAGTCT & livJ (0398) & +154 \\
\hline livJquantrev & TTGAAGCCTCAGCATTTTCAG & livJ (0398) & +289 \\
\hline relAquantfor & GGAGCAGTTGGCTGAAAATC & relA $(0200)$ & +350 \\
\hline relAquantrev & GCTCCTGCTTATCCTTACGAA & relA $(0200)$ & +484 \\
\hline murEquantfor & TTGTGCCAGAGCAAATCAAAG & murE (1233) & +838 \\
\hline murEquantrev & GGCTAGCTCCAACTGGATTC & murE (1233) & +964 \\
\hline ilvCquantfor & TAAAGGGCAGGTACACCAAAA & $i l v C(1848)$ & +452 \\
\hline ilvCquantrev & GTTTTGCTCACGGTTTCAACA & $i l v C(1848)$ & +313 \\
\hline ilvBquantfor & AGCCAATTCTTGGTTCGTCAT & $i l v B(1850)$ & +1368 \\
\hline ilvBquantrev & GGCCTTGGAACTATGGGATT & $i l v B(1850)$ & +1245 \\
\hline dtptquantfor & AACGTTCTGTTGCCGTAACC & $d t p T(0984)$ & +838 \\
\hline dtptquantrev & CGTTGTGATGAACCTTGTCG & $d t p T(0984)$ & +704 \\
\hline bcaTquantfor & CCAGCCCTTCACTATGGTC & bcaT $(0635)$ & +141 \\
\hline bcaTquantrev & GGCATCAAAAGACGATCAGCA & bcaT $(0635)$ & +275 \\
\hline pepCquantfor & GGACAATGGGATATGGTCGA & pepC (0276) & +434 \\
\hline pepCquantrev & GATTTGGGCATCTTGACGAAG & рерC (0276) & +555 \\
\hline pepNquantfor & CGTCTTCTAGCGGAAAGTGG & $\operatorname{pepN}(1012)$ & +1659 \\
\hline pepNquantrev & CGTTTCAAACCAGCAAGGATT & $\operatorname{pepN}(1012)$ & +1784 \\
\hline pepXquantfor & AGGGAGACTTGCTCGTCAAA & pepXP (1633) & +679 \\
\hline pepXquantrev & AGTGTGAGCAAAACGCTCCT & pepXP (1633) & +804 \\
\hline \multirow[t]{2}{*}{ codYquantforprim } & GATAAGGTCGTCGTCCACAA & $\operatorname{cod} Y(1599)$ & +435 \\
\hline & ACCATCTTCCCAGTGGAATTA & $\operatorname{cod} Y(1599)$ & +297 \\
\hline codYquantrevprim & AATGCTTTAGCAGATGGTAAGT & prtS (0846) & +2898 \\
\hline prtSquantforprim & CATAGGTAGCTGTGGTGATAA & prtS (0846) & +3031 \\
\hline prtSquantrevprim & CCAAATGGCTGTCATCCTCT & $\sigma 70 / \sigma 32(1448)$ & +826 \\
\hline F-sigmaquantfor & GACCCAACACCTGAGCAAAT & $\sigma 70 / \sigma 32(1448)$ & +696 \\
\hline F-sigmaquantrev & & & \\
\hline
\end{tabular}

\footnotetext{
${ }^{\mathrm{a}}$ Gene number according to the genome of Streptococcus thermophilus LMD-9

${ }^{\mathrm{b}}$ Relative position in base pair from the ATG of the corresponding gene (- upstream, + downstream)
}

acidifying properties were significantly different (Galia et al. 2009). Firstly, we followed their growth at $42{ }^{\circ} \mathrm{C}$ in $\mathrm{M} 17$ and milk media by $\mathrm{pH}$ measurement and determination of cell density. 
In M17 medium, the growth of both strains appeared to be similar (results not shown). The time required to decrease from an extracellular $\mathrm{pH}$ of 6 to an extracellular $\mathrm{pH}$ of 5 (i.e., precisely in the exponential growth phase) was approximately the same for both strains (around $50 \mathrm{~min}$ ). The maximum $\mathrm{OD}_{650} \mathrm{~nm}$ reached at the end of the exponential phase was about 3.6 \pm 0.1 for PB302 and about $3.4 \pm 0.2$ for PB18O.

In milk, the differences in growth between the two strains were significantly marked: the time required to reach an extracellular $\mathrm{pH}$ of 5 from an initial $\mathrm{pH}$ of 6 was 86.5 $\pm 9.2 \mathrm{~min}$ for $\mathrm{PB} 302$ versus $122.5 \pm 3.5 \mathrm{~min}$ for $\mathrm{PB} 18 \mathrm{O}$ strain. Moreover, the maximum $\mathrm{OD}_{480 \mathrm{~nm}}$ reached at the end of the exponential phase was 5.8 for PB302 versus 3.3 for PB18O.

\subsection{Expression of prtS in PB302 and PB18O during growth in milk and M17 media}

The expression of the prtS gene was followed during growth of PB302 and PB18O strains in milk and M17 media at two levels: transcriptional and posttranslational. For the first, the expression of prtS was determined by qRT-PCR, whereas for the second, the cell surface proteolytic activity was measured by incubating cells with the chromogenic substrate Suc-Ala-Ala-Pro-Phe- $p$ Na. For M17 cultures, we focused on four stages of growth: early exponential phase $\left(\mathrm{OD}_{650 \mathrm{~nm}}=0.7\right)$; late exponential phase $\left(\mathrm{OD}_{650 \mathrm{~nm}}=2\right)$; early stationary phase $\left(\mathrm{OD}_{650 \mathrm{~nm}}=4\right)$; and $2 \mathrm{~h}$ after the beginning of the stationary phase $\left(\mathrm{OD}_{650 \mathrm{~nm}}=4.2\right)$. For milk medium, only two points were analyzed: early (extracellular $\mathrm{pH}$ 6) and late (extracellular $\mathrm{pH} 5.3$ ) exponential phase because when bacterial cells reached the stationary phase, the milk coagulated which prevented the cell recovery and the obtaining of mRNA of sufficient quality.

\subsubsection{Estimation of the cell surface proteolytic activity using synthetic substrate}

As specified before, the proteinase activities of Streptococcus thermophilus PB302 and PB18O grown in milk and M17 media were followed by incubating cells with the chromogenic substrate Suc-Ala-Ala-Pro-Phe- $p$ Na. To be sure that the detected proteolytic activity was due to the activity of PrtS and not to intracellular peptidases released from lysis, cells of the two strains were incubated in Tris-HCl buffer without substrate, then eliminated by centrifugation and culture supernatants were incubated with the synthetic substrate Lys- $p$ NA to detect potential peptidase activity. As expected, no peptidase activity was detected with the Lys- $p$ NA substrate for both strains and at each stages of growth tested. Proteinase activities are reported in Table 2.

During growth in M17, the PB180 strain exhibited very little cell surface proteolytic activity (Table 2A). The proteolytic activity observed for PB302 was higher than that for the strain PB180 whatever the growth time tested. Indeed, the cell-surface proteolytic activity was 5-8-fold higher with the strain PB302 than with PB180 for the first three points tested (early/late exponential phase; early stationary phase) and up to 30 -fold higher for the late stationary phase. For both strains, the proteinase activity was maximal throughout the exponential growth 
Table 2 Cell envelope-associated proteinase activities ${ }^{\mathrm{a}}$ (milli absorbance unit at $410 \mathrm{~nm}$ ) of Streptococcus thermophilus PB302 and PB180 grown in M17 medium (A) or in milk (B)

\begin{tabular}{|c|c|c|c|c|}
\hline \multicolumn{5}{|l|}{ A. } \\
\hline Strains & $\begin{array}{l}\text { Early exponential phase } \\
\left(\mathrm{OD}_{650 \mathrm{~nm}}=0.7\right)\end{array}$ & $\begin{array}{l}\text { Late exponential phase } \\
\left(\mathrm{OD}_{650 \mathrm{~nm}}=2\right)\end{array}$ & $\begin{array}{l}\text { Early stationary phase } \\
\left(\mathrm{OD}_{650 \mathrm{~nm}}=4\right)\end{array}$ & $\begin{array}{l}\text { Late stationary phase } \\
\left(\mathrm{OD}_{650 \mathrm{~nm}}=4.2\right)\end{array}$ \\
\hline PB18O & $30 \pm 1$ & $40 \pm 1$ & $10 \pm 2$ & $1 \pm 0.1$ \\
\hline PB302 & $210 \pm 10$ & $210 \pm 4$ & $80 \pm 2$ & $30 \pm 1$ \\
\hline \multicolumn{5}{|l|}{ B. } \\
\hline Strains & $\begin{array}{l}\text { Early exponential phase } \\
(\mathrm{pH}=6)\end{array}$ & & $\begin{array}{l}\text { Late exponential phase } \\
(\mathrm{pH}=5.3)\end{array}$ & \\
\hline PB18O & $120 \pm 30$ & & $210 \pm 20$ & \\
\hline PB302 & $410 \pm 60$ & & $520 \pm 10$ & \\
\hline
\end{tabular}

All the values are expressed as mean \pm SEM (standard error of the mean expression fold change)

${ }^{a}$ Assays were performed in triplicate on cells obtained from two independently grown cultures

phase but dropped sharply at the beginning of stationary phase, reaching a very low value in the late stationary phase.

In milk, the proteolytic activity observed for both strains appeared to be higher than that for M17 medium (Table 2B). For both strains, activity is higher at late exponential phase than at the beginning, and at late exponential phase, the strains PB302 and PB18O exhibited, respectively, 2.5 and 5-fold higher proteolytic activities than did the same strains grown in the M17 broth. As observed in M17, the proteolytic activity detected with PB302 remained significantly higher than that of PB18O, around 3-fold higher.

\subsubsection{Quantification of the expression of the prtS gene}

The expression of the prtS gene was followed during the growth in milk and M17 media of Streptococcus thermophilus PB302 and PB18O. At each stage of growth tested, RNAs were extracted and reverse transcribed in cDNA. Specific cDNA corresponding to $p r t S$ were searched using the primers PrtSquantforprim/PrtSquantrevprim (Table 1). For cell grown in M17, mRNAs of sufficient quality were obtained for three points (early and late exponential phases and early stationary phase). For cells grown in milk, mRNAs extracted in the early and in the late exponential phase were of sufficient quality for the strain PB302 but not for the strain PB18O, for which only mRNAs of sufficient quality were extracted from the late exponential phase. As the proteolytic activity appeared to be constant throughout the exponential phase in M17 and highest in late exponential phase in milk (Table 2), we considered that these points were informative enough.

In M17, the level of expression of $p r t S$ appeared to be constant over time even if it seemed to increase (2-fold) at the early stationary phase for the PB302 strain (results not shown). The comparison of the expression level of prtS between the two strains (Table 3) showed that the prtS gene was more expressed in PB302 compared to PB180, especially in early stationary phase (7-fold).

In milk, as observed in M17, PB302 presented a transcription level much higher than that of the PB18O strain (about 5-fold) (Table 3). 
Table 3 Fold change (FC) values ${ }^{\mathrm{a}}$ in the mean transcript levels of the prtS gene in $\mathrm{PB} 302$ relative to $\mathrm{PB} 18 \mathrm{O}$ cultures sampled in different growth phases in M17 medium or in milk

\begin{tabular}{|c|c|c|}
\hline Medium & Phase of growth & Mean $\mathrm{FC} \pm \mathrm{SEM}^{\mathrm{b}}$ \\
\hline \multirow[t]{3}{*}{ M17 } & $\begin{array}{l}\text { Early exponential phase } \\
\left(\mathrm{DO}_{650 \mathrm{~nm}}=0.7\right)\end{array}$ & $4.03 \pm 0.52$ \\
\hline & $\begin{array}{l}\text { Late exponential phase } \\
\left(\mathrm{DO}_{650 \mathrm{~nm}}=2\right)\end{array}$ & $2.53 \pm 0.65$ \\
\hline & $\begin{array}{l}\text { Early stationary phase } \\
\left(\mathrm{DO}_{650 \mathrm{~nm}}=4\right)\end{array}$ & $7.47 \pm 2.67$ \\
\hline Milk & $\begin{array}{l}\text { Late exponential phase } \\
(\mathrm{pH}=5.3)\end{array}$ & $5.70 \pm 2.36$ \\
\hline
\end{tabular}

${ }^{\mathrm{a}}$ Fold changes are means from PCR performed in triplicate on RNA purified from two independently grown cultures

${ }^{\mathrm{b}}$ Standard error of the mean expression fold change

\subsection{Quantification of the expression of genes involved in nitrogen and carbon metabolism in Streptococcus thermophilus}

To understand the difference in the acidifying capacity between the two strains, PB18O and PB302, we decided to analyze for the first time the presence/absence of other genes known to be involved in the nitrogen or carbon metabolism, and for the second time, their expression levels. Thirteen genes were selected (Table 4). These genes are involved in transport of peptides or amino acid (ami operon, livJ, $d t p T$ ), in amino acid

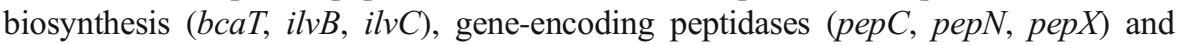
transcriptional regulators (relA, $\operatorname{cod} Y$ ), and genes involved in carbon metabolism (ackA, $l d h)$. First, one possible link between fast acidifying phenotype and genetic equipment was investigated by comparing their corresponding gene set determined by PCR. Genetic profiles did not appear to be linked to acidifying capacity because all the selected genes were detected in the two strains. These genes were then sequenced in both strains, including the promoter region (about $400 \mathrm{pb}$ ). No difference was observed between the two strains, neither in the open reading frames nor in the promoter/ regulatory regions, indicating that the difference in acidifying capacity was not due to a mutation in one of these genes but perhaps a different transcriptional regulation. The analysis of their promoter region revealed that most of them harbored a putative CodYbox, which was deduced by searching for sequences resembling consensus sequence determined by den Hengst et al. (2005) (Table 4).

Their expression has thus been followed during growth in milk and M17 using the same cDNA as those used for the quantification of prtS.

During the growth in M17, when comparing the transcription level of the different genes between the two strains (Table 5), it appears that most of them are expressed similarly, which is consistent with the similarity of the growth curves of these strains in this medium. Only a few genes are expressed differently: bcaT is less expressed in PB302 at the three stages of growth tested; $a m i F$ (so the ami operon) is less expressed in PB302 in early stationary phase; on the contrary, liv $J$ and ackA are more expressed in PB302 in early stationary phase (Table 5). 
Table 4 Genes analyzed in real-time reverse transcription PCR experiments

\begin{tabular}{|c|c|c|c|c|}
\hline $\begin{array}{l}\text { Gene } \\
\text { name }\end{array}$ & $\begin{array}{l}\text { Locus } \\
\left(_{\text {STER_no. }}\right)^{\mathrm{a}}\end{array}$ & Functional assignment & CodY box ${ }^{b}$ & $\begin{array}{l}\text { Distance } \\
\text { from } \\
\text { AUG }^{\mathrm{c}}\end{array}$ \\
\hline
\end{tabular}

AA/peptide transporter

$\begin{array}{ll}\text { amiF } & (1405) \\ \text { dtpT } & (0984) \\ \text { liv } J & (0398)\end{array}$

Peptidases, proteases

\begin{tabular}{|c|c|c|}
\hline рерC & $(0276)$ & Cysteine aminopeptidase $\mathrm{C}$ \\
\hline pepN & (1012) & $\begin{array}{l}\text { Lysyl-aminopeptidase, } \\
\text { aminopeptidase } \mathrm{N}\end{array}$ \\
\hline pepX & (1633) & X-prolyl dipeptidyl peptidase \\
\hline prtS & $(0846)$ & Subtilisin-like serine protease \\
\hline
\end{tabular}

Transcriptional regulator

$\operatorname{cod} Y$

relA

AA metabolism

bcaT
$i l v C$
$i l v B$

C-metabolism

ackA

$l d h$

Reference gene

$$
\sigma 70 / 32 \quad \text { (1448) }
$$
Branched chain amino acid aminotransferase

Ketol-acid reductoisomerase

Acetolactate synthase (ilvDBN)

Acetate kinase

L-lactate dehydrogenase

DNA-directed RNA polymerase, sigma subunit $(\sigma 70 / \sigma 32)$
Oligopeptide $\mathrm{ABC}$ transporter (amiACDEF)

Di/tripeptide transporter

Branched-chain AA transporter (livJHMGF)

\section{Transcriptional pleiotropic repressor CodY
Guanosine polyphosphate pyrophosphohydrolase/ synthetase ((p)ppGpp synthetase)

ATTATTCTGAAAAAT $\quad-106$

AATTTTCTGATAATT $\quad-50$

AATTTTCAGAAAtTA $\quad-42$

AAaTATCAGTCTgTT $\quad-34$

ATaTTTCTGgAAtAT $\quad-28$

AATTTTCAGAATATA $\quad-96$

AATTTTCAGACAATT $\quad-117$

\author{
AATTGTCAGAATtTT $\quad-75$ \\ AATCGTCAGATTgAT $\quad-342$ \\ gAaTTACAGAAAtAT $\quad-88$ \\ gGaAATCAGATAATT -66
}

Small letters indicate mismatches from the derivatives of the consensus sequence AATTTTCWGAAAATT established by den Hengst et al. (2005) in Lactococcus lactis (W= A or T)

${ }^{a}$ Based on annotation of the LMD-9 genome (Bolotin et al. 2004; Makarova et al. 2006).

${ }^{\mathrm{b}}$ Sequences obtained from the strains PB302 and PB18O

${ }^{\mathrm{c}}$ Relative position in base pairs of the CodY-box relative to the translational start codon (AUG) of the corresponding gene (or the first gene of the operon)

In milk, differences appear to be more marked. Four of the tested genes $(\operatorname{cod} Y, i l v C$, $l i v J$, and relA) appeared to be significantly more expressed in the strain PB302 during the late exponential phase in milk. 
Table 5 Fold change (FC) values ${ }^{\mathrm{a}}$ in the mean transcript levels of the listed genes in PB302 relative to PB180 cultures sampled in early, late exponential or early stationary phase of growth in M17 medium and late exponential phase of growth in milk

\begin{tabular}{|c|c|c|c|c|}
\hline \multirow[b]{2}{*}{ Gene } & \multicolumn{3}{|l|}{ M17 } & \multirow{2}{*}{$\begin{array}{l}\text { Milk } \\
\text { Late exponential phase }\end{array}$} \\
\hline & Early exponential phase & Late exponential phase & Early stationary phase & \\
\hline amiF & $0.80 \pm 0.04$ & $0.52 \pm 0.17$ & $\underline{0.19} \pm 0.02$ & $1.11 \pm 0.44$ \\
\hline$d t p T$ & $2.76 \pm 2.50$ & $1.52 \pm 0.27$ & $2.98 \pm 1.98$ & $1.82 \pm 1.33$ \\
\hline livJ & $1.84 \pm 0.64$ & $1.19 \pm 0.83$ & $\underline{7.28} \pm \mathbf{2 . 6 2}$ & $\underline{2.71 \pm 0.06}$ \\
\hline рерC & $2.31 \pm 1.21$ & $1.27 \pm 0.48$ & $1.54 \pm 0.91$ & $2.25 \pm 1.92$ \\
\hline pepN & $1.18 \pm 0.36$ & $1.30 \pm 0.56$ & $0.82 \pm 0.13$ & $1.06 \pm 0.10$ \\
\hline pepX & $1.23 \pm 0.21$ & $1.09 \pm 0.20$ & $1.75 \pm 0.21$ & $0.88 \pm 0.47$ \\
\hline $\operatorname{cod} Y$ & $1.21 \pm 0.95$ & $0.80 \pm 0.10$ & $2.23 \pm 0.60$ & $\underline{3.92 \pm 0.84}$ \\
\hline relA & $0.94 \pm 0.35$ & $1.11 \pm 0.16$ & $1.38 \pm 0.29$ & $\underline{2.65} \pm 0.69$ \\
\hline bcaT & $\underline{0.40 \pm 0.16}$ & $\underline{0.34 \pm 0.11}$ & $\underline{0.28 \pm 0.16}$ & $1.40 \pm 1.16$ \\
\hline$i l v C$ & $1.19 \pm 0.46$ & $1.59 \pm 0.46$ & $1.90 \pm 0.57$ & $\underline{4.20 \pm 0.73}$ \\
\hline$i l v B$ & $1.33 \pm 0.57$ & $1.42 \pm 0.06$ & $1.43 \pm 0.49$ & $6.48 \pm 5.16$ \\
\hline ackA & $1.66 \pm 1.09$ & $1.71 \pm 0.24$ & $\underline{2.03} \pm 0.04$ & $3.62 \pm 2.19$ \\
\hline$l d h$ & $0.60 \pm 0.15$ & $0.65 \pm 0.24$ & $0.86 \pm 0.10$ & $1.13 \pm 0.59$ \\
\hline
\end{tabular}

Standard error of the mean expression fold change was calculated for all the values. Values in bold and underlined represent an expression ratio higher than 2 or lesser than 0.5 observed in the two independent experiments

${ }^{\text {a }}$ Fold changes are means from PCR performed in triplicate on RNA purified from two independently grown cultures

Interestingly, when we consider only the strain PB302, none of the tested genes was less expressed in milk than in M17. Indeed, eight genes $(\operatorname{cod} Y, d t p T, a m i F, i l v C, i l v B$, bcaT, liv $J$, and ackA) were more expressed in milk than in M17 at the early exponential phase and three at the late exponential phase (Table 6). In contrast, for PB18O, the expression of the tested genes appeared to be similar between the two media (data not shown). This suggests that the genes overexpressed in milk in PB302 could be important for an optimal growth in milk and that their non-induction in PB18O could be responsible for the slow growth of this strain in milk.

\section{Discussion}

In a previous work, we showed that strains of Streptococcus thermophilus harboring the same allele of the prtS gene presented significantly different acidification capacity and growth rate in milk (Galia et al. 2009), as it is the case of the strains PB302 and PB18O selected for this study. We showed that these strains had a similar growth in M17 medium while in milk, the PB180 strain acidified more slowly and reached a maximum $\mathrm{OD}_{650 \mathrm{~nm}}$ lower than that of the PB302 strain. Hence, we formulated the hypothesis that this difference could mainly result from a difference in the expression of the proteolytic system between the two strains. Indeed, both media contain lactose as 
Table 6 Fold change (FC) values ${ }^{\mathrm{a}}$ in the mean transcript levels of the listed genes in PB302 cultures sampled of growth in milk relative to M17 medium

\begin{tabular}{lll}
\hline Gene & Early exponential phase & Late exponential phase \\
\hline $\begin{array}{ll}\text { ack } A \\
\text { amiF }\end{array}$ & $\frac{\mathbf{1 4 . 1 4} \pm \mathbf{2 . 6 7}}{\mathbf{3 . 1 4} \pm \mathbf{1 . 1 6}}$ & $\frac{\mathbf{2 . 5 6} \pm \mathbf{0 . 0 3}}{2.47 \pm 0.98}$ \\
bcaT & $\underline{\mathbf{4 . 0 7} \pm \mathbf{1 . 6 8}}$ & $1.77 \pm 0.40$ \\
codY & $\underline{\mathbf{6 . 8 0} \pm \mathbf{0 . 9 8}}$ & $\underline{\mathbf{2 , 8 3} \pm \mathbf{0 . 7 7}}$ \\
$d t p T$ & $\underline{\mathbf{3 . 0} \pm \mathbf{0 . 5 2}}$ & $2.34 \pm 1.17$ \\
$i l v B$ & $\underline{\mathbf{6 . 2 2} \pm \mathbf{3 . 1 8}}$ & $\underline{\mathbf{4 . 6 2} \pm \mathbf{2 . 1 2}}$ \\
$i l v C$ & $\frac{\mathbf{2 0 . 3 0} \pm \mathbf{1 4 . 5 2}}{1.45 \pm 0.64}$ & $2.32 \pm 1.16$ \\
$l d h$ & $\underline{\mathbf{3 . 6 4} \pm \mathbf{1 . 7 2}}$ & $0.87 \pm 0.14$ \\
$l i v J$ & $1.80 \pm 0.26$ & $1.28 \pm 0.01$ \\
pepC & $1.20 \pm 0.64$ & $0.51 \pm 0.28$ \\
pep $X$ & $1.94 \pm 0.42$ & $1.17 \pm 0.68$ \\
pepN & $1.08 \pm 0.21$ & $1.0 \pm 0.09$ \\
relA & & $1.21 \pm 0.23$ \\
\hline
\end{tabular}

Standard error of the mean expression fold change was calculated for all the values. Values in bold and underlined represent an expression ratio higher than 2 or lesser than 0.5 observed in the two independent experiments

${ }^{a}$ Fold changes are means from PCR performed in triplicate on RNA purified from two independently grown cultures

the carbon source, but M17 contains an immediately available nitrogen source contrary to the milk. In M17, bacterial cells do not require the cell surface proteolytic activity to benefit from a source of nitrogen, in opposition to milk in which strains expressing a proteolytic system could be advantaged.

So, we were committed to explain these differences of growth by comparing the expression of the prtS gene by quantitative RT-PCR and measurement of the cell surface proteolytic activity in these two strains. The quantitative RT-PCR results demonstrated that the prtS gene was more expressed in PB302 than in PB18O, either in M17 or in milk, the difference being more pronounced in milk during late exponential phase. The quantitative RT-PCR results were corroborated by the measure of the cell surface proteolytic activity using the synthetic substrate Suc-Ala-Ala-Pro-Phe$p$ NA. Thus, the culture medium, probably through the available nitrogen source, had a significant effect on the expression and hence on the activity of the PrtS proteinase of the strains PB302 and PB18O. Indeed, the M17 medium is rich in peptides and free amino acids whereas milk is principally composed of complex proteins. Similar observations have been made for proteinase production in different streptococcal and lactococcal strains. Indeed, the cell wall proteinases of Streptococcus thermophilus CNRZ703 and Lactococcus lactis subsp. lactis NCDO 763 are inducible according to the growth medium (Monnet et al. 1987; Shahbal et al. 1993). In our conditions, a cell surface proteolytic activity was observed over time for the two strains and regardless of the medium. Letort et al. (2002) highlighted a diauxic growth of Streptococcus thermophilus in milk, the protease PrtS being expressed only during the second phase. 
For PB302 and PB180, as well as for the other PrtS+ strains of our collection, a cell surface proteolytic activity was detected from the early exponential phase of growth in both mediums. This suggests that the regulation of prtS could differ from one strain to another.

All these results therefore suggest that the difference of growth rate in milk between the two strains could be explained by a difference of $p r t S$ expression since the PB302 strain, which possesses a high acidifying capacity, has a higher cell surface proteolytic activity and a higher prtS expression level than the other one has. Moreover, in the M17 medium, the acidification rate was similar between the two strains, whereas both the $p r t S$ expression level and the cell surface proteolytic activity were higher in PB302 compared to PB18O. These findings support that other components could be involved in acidification rate.

We decided to enlarge the quantitative RT-PCR experiments to 13 other genes known to be involved in nitrogen or carbon metabolism. Firstly, these genes were sequenced and for each of them, the same allelic version was found in both strains. Most of these genes harbored a CodY-box in their promoter region. At the expression level, most of the genes were expressed at a similar rate in the two strains in M17 medium, whereas in milk, some genes, particularly those involved in nitrogen metabolism, appeared to be more expressed in the strain PB302. Of the five genes overexpressed in milk in PB302 compared to PB18O ( $\operatorname{cod} Y$, ilvC, livJ, prtS, and relA), all but relA possess upstream of their promoter a CodYbox, deduced from the consensus sequence determined by den Hengst et al. (2005), and could therefore belong to the CodY regulon. It is interesting to note that we detected upstream of these genes only one CodY-box which differs from that established in Lactococcus lactis where several CodY-box were detected upstream certain genes or operons highly regulated by CodY (den Hengst et al. 2005). Our results support what was previously reported by Lu et al. (2015) who have shown in the ST2017 strain of Streptococcus thermophilus that CodY regulated among others $i l v B$, ilvC, livJ, and bcaT. Moreover, recent studies demonstrated in vitro a direct interaction of CodY with a number of functional promoters of Streptococcus thermophilus including that of prtS (Liu et al. 2009) and $\operatorname{liv} J$ (Lu et al. 2015).

The differences in gene expression between the two strains PB302 and PB18O were more pronounced in milk than in M17, during the late exponential phase. In addition, it is interesting to note that when we consider only one strain, the nine genes ( codY,dtpT, amiF, $i l v C$, ilvB, bcaT, livJ, prtS, and ackA) overexpressed in milk in PB302 could be important for an optimal growth in milk and that their non-induction in $\mathrm{PB} 18 \mathrm{O}$ could be responsible for the slow growth of this strain in milk. These genes are involved in the proteolytic system ( $p r t S, d t p T, a m i F)$ and synthesis/transport of branched chain amino acids ( $b c a T, i l v B, i l v C$, livJ), which is consistent for milk growth. The cellular role of $a c k A$ is 2 -fold. The coupled activities of phosphotransacetylase and acetate kinase generate ATP by substrate-level phosphorylation. This activity can be an important source of ATP during fermentative growth. In addition, excretion of acetate is a means of removing excess end-products of glucose metabolism (e.g., pyruvate and acetyl CoA) (Dauner et al. 2001).

Except $d t p T$, all the genes mentioned above possess a potential CodY-box and might therefore belong to the same regulon. This means that CodY could play a key role in the regulation of gene expression in milk. In PB302, the overexpression of $i l v B$, ilvC, and $l i v J$ genes in milk should allow the intracellular concentration of BCAA to increase and therefore CodY to be active, as proposed by den Hengst et al. (2005). 


\section{Conclusion}

In conclusion, the regulation of genes involved in nitrogen metabolism is complex in Streptococcus thermophilus. To our knowledge, gene expression of LAB linked to acidifying capacity is not frequently reported in the literature. The difference in acidifying capacity between Streptococcus thermophilus strains could be due to the differential expression of several metabolic-related genes. If PB302 and PB18O have both acquired the same allele of the prtS gene by horizontal gene transfer, the regulation scheme in which it is inserted determined its potential for expression. CodY could also play an important role in the acidifying capacity of Streptococcus thermophilus through the regulation of nitrogen and carbon metabolism. Moreover, a deep understanding of prtS regulatory mechanisms may help to improve Streptococcus thermophilus growth in milk.

Acknowledgments This work was supported by "Le Ministère de l'Enseignement Supérieur et de la Recherche".

\section{Compliance with ethical standards}

Conflict of interest The authors declare that they have no conflict of interest.

\section{References}

Belintsky BR, Sonenshein AL (2008) Genetic and biochemical analysis of CodY-binding sites in Bacillus subtilis. J Bacteriol 190:1224-1236

Bolotin A, Quinquis B, Renault P, Sorokin A, Ehrlich SD, Kulakauskas S, Lapidus A, Goltsman E, Mazur M, Pusch GD, Fonstein M, Overbeek R, Kyprides N, Purnelle B, Prozzi D, Ngui K, Masuy D, Hancy F, Burteau S, Boutry M, Delcour J, Goffeau A, Hols P (2004) Complete sequence and comparative genome analysis of the dairy bacterium Streptococcus thermophilus. Nat Biotechnol 22:1554-1558

Broadbent JR, Cai H, Larsen RL, Hughes JE, Welker DL, De Carvalho VG, Tompkins TA, Ardö Y, Vogensen F, De Lorentiis A, Gatti M, Neviani E, Steele JL (2011) Genetic diversity in proteolytic enzymes and amino acid metabolism among Lactobacillus helveticus strains. J Dairy Sci 94:4313-4328

Chomczynski P (1993) A reagent for the single-step simultaneous isolation of RNA. DNA and proteins from cell and tissue samples. Biotechniques 15(532-534):536-537

Chomczynski P, Sacchi N (1987) Single-step method of RNA isolation by acid guanidinium thiocyanatephenol-chloroform extraction. Anal Biochem 162:156-159

Chopard MA, Schmitt M, Perreard E, Chamba JF (2001) Aspect qualitatif de l'activité protéolytique des lactobacilles thermophiles utilisés en fabrication de fromages à pâte pressée cuite. Lait 81:183-194

Courtin P, Monnet V, Rul F (2002) Cell-wall proteinases PrtS and PrtB have a different role in Streptococcus thermophilus/Lactobacillus bulgaricus mixed cultures in milk. Microbiology 148:3413-3421

Dandoy D, Fremaux C, de Frahan MH, Horvath P, Boyaval P, Hols P, Fontaine L (2011) The fast milk acidifying phenotype of Streptococcus thermophilus can be acquired by natural transformation of the genomic island encoding the cell-envelope proteinase PrtS. Microb Cell Factories 10(Suppl 1):S21

Dauner M, Storni T, Sauer U (2001) Bacillus subtilis metabolism and energetics in carbon-limited and excesscarbon chemostat culture. J Bacteriol 183:7308-7317

Delorme C, Bartholini C, Bolotine A, Dusko Ehrlich S, Renault P (2010) Emergence of a cell wall protease in the Streptococcus thermophilus population. Appl Environ Microbiol 76:451-460

den Hengst CD, van Hijum SA, Geurts JM, Nauta A, Kok J, Kuipers OP (2005) The Lactococcus lactis CodY regulon: identification of a conserved cis-regulatory element. J Biol Chem 280:34332-34342

Derzelle S, Bolotin A, Mistou MY, Rul F (2005) Proteome analysis of Streptococcus thermophilus grown in milk reveals pyruvate formate-lyase as the major upregulated protein. Appl Environ Microbiol 71:85978605 
Galia W, Perrin C, Genay M, Dary A (2009) Variability and molecular typing of Streptococcus thermophilus strains displaying different proteolytic and acidifying properties. Int Dairy J 19:89-95

Genay M, Sadat L, Gagnaire V, Lortal S (2009) prtH2, Not prtH, is the ubiquitous cell wall proteinase gene in Lactobacillus helveticus. Appl Environ Microbiol 75:3238-3249

Green MR, Sambrook J (2012) Molecular cloning: a laboratory manual. Cold Spring Harbor Laboratory Press, N. Y

Guédon E, Sperandio B, Pons N, Ehrlich SD, Renault P (2005) Overall control of nitrogen metabolism in Lactococcus lactis by CodY, and possible models for CodY regulation in Firmicutes. Microbiology 151: 3895-3909

Guimont C, Chopard MA, Gaillard JL, Chamba JF (2002) Comparative study of the protein composition of three strains of Streptococcus thermophilus grown either in M17 medium or in milk. Lait 82:645-656

Hendriksen WT, Bootsma HJ, Estevao S, Hoogenboezem T, de Jong A, de Groot R, Kuipers OP, Hermans PW (2008) CodY of Streptococcus pneumoniae: link between nutritional gene regulation and colonization. J Bacteriol 190:590-601

Junjua M, Kechaou N, Chain F, Awussi AA, Roussel Y, Perrin C, Roux E, Langella P, Bermúdez-Humarán LG, Le Roux Y, Chatel JM, Dary-Mourot A (2016) A large scale in vitro screening of Streptococcus thermophilus strains revealed strains with a high anti-inflammatory potential. LWT-Food Sci Technol. doi: 10.1016/j.lwt.2016.02.006

Letort C, Nardi M, Garault P, Monnet V, Juillard V (2002) Casein utilization by Streptococcus thermophilus results in a diauxic growth in milk. J Appl Microbiol 68:3162-3165

Liu F, Du L, Du P, Huo G (2009) Possible promoter regions within the proteolytic system in Streptococcus thermophilus and their interaction with the CodY homolog. FEMS Microbiol Lett 297:164-172

Livak KJ, Schmittgen TD (2001) Analysis of relative gene expression data using real-time quantitative PCR and the 2( $\left.{ }^{-\Delta \Delta \mathrm{Ct}}\right)$ method. Methods Enzymol 25:402-408

Lu WW, Wang Y, Wang T, Kong J (2015) The global regulator CodY in Streptococcus thermophilus controls the metabolic network for escalading growth in the milk environment. Appl Environ Microbiol 81:23492358

Makarova K, Slesarev A, Wolf Y, Sorokin A, Mirkin B, Koonin E, Pavlov A, Pavlova N, Karamychev V, Polouchine N, Shakhova V, Grigoriev I, Lou Y, Rohksar D, Lucas S, Huang K, Goodstein DM, Hawkins T, Plengvidhya V, Welker D, Hughes J, Goh Y, Benson A, Baldwin K, Lee JH, Díaz-Muñiz I, Dosti B, Smeianov V, Wechter W, Barabote R, Lorca G, Altermann E, Barrangou R, Ganesan B, Xie Y, Rawsthorne H, Tamir D, Parker C, Breidt F, Broadbent J, Hutkins R, O’Sullivan D, Steele J, Unlu G, Saier M, Klaenhammer T, Richardson P, Kozyavkin S, Weimer B, Mills D (2006) Comparative genomics of the lactic acid bacteria. Proc Natl Acad Sci U S A 103:15611-15616

Monnet V, Bars DL, Neviani E, Gripon JC (1987) Partial characterization and comparison of cell wall proteinases from 5 strains of Streptococcus lactis. Lait 67:51-61

Preis H, Eckart RA, Gudipati RK, Heindrich N, Brantl S (2009) CodY activates transcription of a small RNA in Bacillus subtilis. J Bacteriol 191:5446-5457

Savijoki K, Ingmer H, Varmanen P (2006) Proteolytic systems of lactic acid bacteria. Appl Microbiol Biotechnol 71:394-406

Shahbal S, Hemme D, Renault P (1993) Characterization of a cell envelope-associated proteinase activity from Streptococcus thermophilus H-strains. Appl Environ Microbiol 59:177-182

Shivers RP, Dineen SS, Sonenshein AL (2006) Positive regulation of Bacillus subtilis ackA by CodY and CcpA: establishing a potential hierarchy in carbon flow. Mol Microbiol 62:811-822

Terzaghi BE, Sandine WE (1975) Improved medium for lactic Streptococci and their bacteriophages. Appl Microbiol 29:807-813

Thomas TD, Turner KW (1977) Preparation of skim milk to allow harvesting of starter cells from milk cultures. NZ J Dairy Sci Technol 12:15-21

Untergasser A, Nijveen H, Rao X, Bisseling T, Geurts R, Leunissen JAM (2007) Primer3Plus, an enhanced web interface to Primer3. Nucleic Acids Res 35:W71-W74

Urshev Z, Ninova-Nikolova N, Ishlimova D, Pashova-Baltova K, Michaylova M, Savova T (2014) Selection and characterization of naturally occurring high acidification rate Streptococcus thermophilus strains. Biotechnol Biotec Equip 28:899-903 